\title{
Inhibitory Effects of Extracts from Peels of Citrus natsudaidai Encapsulated in Hybrid Liposomes on the Growth of Tumor Cells in Vitro
}

\author{
Yutaka Kadota, ${ }^{a}$ Chiho Taniguchi, ${ }^{b}$ Shigeo Masuhara, ${ }^{c}$ Shinjiro Yamamoto, ${ }^{d}$ Shintaro Furusaki, ${ }^{d}$ \\ Masayoshi Imahara, ${ }^{b}$ Koichi Goto, ${ }^{a, d}$ Yoko Matsumoto, ${ }^{a, d}$ and Ryuichi UeokA $*, a, d$ \\ ${ }^{a}$ Division of Applied Chemistry, Graduate School of Sojo University; ${ }^{b}$ Division of Applied Microbial Technology, \\ Graduate School of Sojo University; 4-22-1 Ikeda, Kumamoto 860-0082, Japan: ${ }^{~}$ Minamata Environmental Technology \\ Development Center Co. Ltd.; 1-1 Noguchi-Cho, Minamata 867-8501, Japan: and ${ }^{d}$ Department of Applied Life Science, \\ Faculty of Engineering, Sojo University; 4-22-1 Ikeda, Kumamoto 860-0082, Japan.
}

Received May 6, 2004; accepted June 28, 2004; published online July 1, 2004

\begin{abstract}
Inhibitory effects of extracts from peels of Citrus natsudaidai (natsumikan) encapsulated in hybrid liposomes (HL) composed of $L$ - $\alpha$-dimyristoylphosphatidylcholine and polyoxyethylene (20) sorbitan monolaurate on the growth of tumor cells were examined. The extracts with lower polar solvents inhibited the growth of B-16 mouse melanoma and human lung carcinoma cells, although the extracts with higher polar solvents showed no antitumor activity. In particular, the inhibitory effects of extracts with lower polar solvents encapsulated in HL were enhanced as compared with those of free extracts. Fluorescence microscopic analysis indicated that the HL including petroleum ether extracts induced apoptosis in B-16 mouse melanoma cells. On the other hand, the viability of normal human fibroblast cells was even less affected by the extracts of natsumikan. These results suggest that hydrophobic antitumor agents should be present in peels of natsumikan.
\end{abstract}

Key words Citrus natsudaidai; hybrid liposome; antitumor effect; apoptosis

Bioactive natural products such as antitumor agents in citrus fruits have attracted much attention in recent years. ${ }^{1-4)}$ For example, auraptene in natsumikan (Citrus natsudaidai), hassaku orange (Citrus hassaku) and grapefruits (Citrus paradise) has been reported to inhibit the carcinogenesis in animal experiments.

Hybrid liposomes (HL), first developed by Ueoka et al., ${ }^{5)}$ can be prepared by simply ultrasonicating a mixture of vesicular and micellar molecules in the buffer solution. It has been reported that HL composed of L- $\alpha$-dimyristoylphosphatidylcholine (DMPC) and polyoxyethylene alkyl ether demonstrated remarkable inhibitory effects on the growth of tumor cells in vitro ${ }^{6}$ and in vivo. ${ }^{7)}$ Recently, successful clinical chemotherapy with drug-free HL to patients with lymphoma has been reported. ${ }^{8)}$ On the other hand, HL composed of DMPC and polyoxyethylene (20) sorbitan monolaurate (Tween 20) including antitumor nitrosoureas have been found to have a highly inhibitory effect on the growth of glioma in vitro and in vivo. ${ }^{9)}$ Furthermore, extracts from the leaf of Ginkgo biloba L. encapsulated in HL had remarkably high inhibitory effects on the growth of B-16 melanoma and RERF-LC-OK cells in vitro. ${ }^{10)}$ These studies showed that the use of HL was effective for improving solubilization and stabilization of hydrophobic drugs in drug delivery systems and for enhancing the therapeutic efficacy.

In this study, we extracted useful components from the peels of natsumikan with a variety of solvents and examined the inhibitory effects of the extracts encapsulated in HL on the growth of tumor cells in vitro. The cytotoxicity of extracts against the normal cells is also reported.

\section{MATERIALS AND METHODS}

Plant Material Fresh peels of Citrus natsudaidai (natsumikan) collected in Kumamoto Prefecture, Japan, in March 1999 were used in this study.

Chemicals Organic solvents for the extraction, petro- leum ether, diethyl ether, chloroform, acetone and ethanol were of reagent grade from Nacalai Tesque (Japan). L- $\alpha$ Dimyristoylphosphatidylcholine (DMPC, NOF, Japan) and polyoxyethylene (20) sorbitan monolaurate (Tween 20, Nacalai Tesque) were obtained commercially and used without further purification. Dulbecco's modified Eagle medium (DMEM) and RPMI 1640 medium were purchased from GIBCO BRL (U.S.A.). Fetal bovine serum (FBS) was from Hyclone (U.S.A.). Auraptene was synthesized according to the method described in ref. $11 . \mathrm{mp} 64.9-65.1^{\circ} \mathrm{C}\left(\right.$ lit. ${ }^{11)} \mathrm{mp}$ $\left.68^{\circ} \mathrm{C}\right)$. IR (KBr) cm ${ }^{-1}: 3060,2902,2856,1731,1238$. Anal. Calcd for $\mathrm{C}_{19} \mathrm{H}_{22} \mathrm{O}_{3}$ : C, 75.36; H, 7.52. Found: C, 76.48; H, 7.43 .

Extraction The peels of natsumikan were lyophilized with a freeze-dryer (IWAKI, FRD-50D, Japan) and pulverized using a grinder. Extractions of the dried powder were carried out in succession with petroleum ether, diethyl ether and chloroform in Soxhlet extractor for each $8 \mathrm{~h}$. The residue was digested in acetone $\left(40-50^{\circ} \mathrm{C}\right)$, ethanol $\left(60-70^{\circ} \mathrm{C}\right)$ and water $\left(70-80^{\circ} \mathrm{C}\right)$ for each $8 \mathrm{~h}$. All the solutions were evaporated under reduced pressure to yield the extracts.

High Performance Liquid Chromatography (HPLC) Auraptene content of extracts of natsumikan was determined by HPLC. The extracts were dissolved in mixed solvent of acetone and methanol $(1: 1)$, and the solution was filtered to remove the insoluble substances. HPLC was performed on ODS column Mightysil RP-18 (Kanto Chemical, Japan) using HITACHI L-6000 pump with L-4200 UV-VIS detector and D-2500 chromato-integrator (Japan).

Preparation of Hybrid Liposomes (HL) HL including extracts of natsumikan were prepared by the method as reported previously. ${ }^{9,10)}$ Briefly, DMPC $\left(3.0 \times 10^{-3} \mathrm{M}\right)$, Tween $20\left(3.3 \times 10^{-4} \mathrm{M}\right)$ and the extracts $(2000 \mu \mathrm{g} / \mathrm{ml})$ were added to the phosphate buffered-saline (PBS (-)), and sonicated with BRANSONIC Model B2210 sonicator (Yamato, Japan) at $45^{\circ} \mathrm{C}$. The sample solutions were sterilized using membrane filter with $0.45 \mu \mathrm{m}$ pore size. 
Light-Scattering Measurements Apparent mean hydrodynamic diameters $\left(d_{\text {hy }}\right)$ of HL including the extracts of natsumikan were measured by dynamic light-scattering method employing BI-90 particle sizer (Brookhaven Instruments, U.S.A.) and Model 127 Stabilite He-Ne laser (SpectraPhysics, U.S.A.).

Cell Culture Human lung adenocarcinoma (RERF-LCOK), Human hepatoma (Hep-G2), human stomach tumor (GT3TKB) and normal human fibroblast (WI-38) cells were obtained from Riken Cell Bank (Japan). B-16 mouse melanoma (B-16 melanoma) cells were purchased from Dainippon Pharmaceutical (Japan). The cells were maintained in DMEM (B-16 melanoma, Hep-G2, GT3TKB, WI38 cells) or RPMI 1640 mediums (RERF-LC-OK cells) containing $10 \% \mathrm{v} / \mathrm{v}$ FBS in a humidified atmosphere of $5 \% \mathrm{CO}_{2}$ at $37^{\circ} \mathrm{C}$.

WST-1 Assay $1.0 \times 10^{4}$ viable cells in $100 \mu$ l of culture medium were inoculated in a 96-well tissue culture plate (Sumilon, Japan) and incubated in a humidified $5 \% \mathrm{CO}_{2}$ incubator at $37^{\circ} \mathrm{C}$. After $24 \mathrm{~h}, 10 \mu \mathrm{l}$ of PBS (-) solutions of the extracts of natsumikan, which were dispersed in PBS (-) with sonication, or HL including the extracts were added to each well. After incubation for $2 \mathrm{~d}$, the cell viability was determined on the basis of WST-1 assay ${ }^{12)}$ with commercial cell counting kit according to the manufacturer's instruction (Dojindo Laboratories, Japan). The inhibitory effects of the extracts on the growth of tumor cells were evaluated by $A_{\text {mean }} / A_{\text {control }}$, where $A_{\text {mean }}$ and $A_{\text {control }}$ denote the absorbance at $450 \mathrm{~nm}$ in the presence and absence of the extracts, respectively. Cytotoxicity of the extracts against the normal WI-38 cells was examined by WST-1 assay in the same manner as described above.

Fluorescence Microscopic Analysis Fluorescence microscopic analysis of tumor cells treated with the extracts encapsulated in HL was performed using Leica TCS-SP confocal laser microscope (Germany) and Vybrant Apoptosis Assay Kit \#4 (Molecular Probes Eugene, U.S.A.). $0.5 \mathrm{ml}$ of PBS (-) solution of HL including extracts was added into $5 \mathrm{ml}$ of cell suspension $\left(5.0 \times 10^{5}\right.$ cells $\left./ \mathrm{ml}\right)$ in culture dish and the dish was incubated for $12 \mathrm{~h}$ at $37^{\circ} \mathrm{C}$ in $5 \% \mathrm{CO}_{2}$ humidified air. After centrifuging and removing the medium, the cells were suspended in $1 \mathrm{ml}$ of cold PBS $(-)$ and stained with each $1 \mu \mathrm{l}$ of YO-PRO-1 $(100 \mu \mathrm{M})$ and propidium iodide (PI, $1.5 \mathrm{~mm}$ ) stock solutions on ice for $30 \mathrm{~min}$. The stained cells were washed and resuspended with PBS (-). The fluorescence microscopic observations of the stained cells were carried out using an $\mathrm{Ar}$ and $\mathrm{He}-\mathrm{Ne}$ lasers for excitation of YO-PRO-1 (excitation/detection $=488 / 495-535 \mathrm{~nm}$ ) and PI $(543 / 580-720 \mathrm{~nm})$, respectively.

\section{RESULTS AND DISCUSSION}

Extracts from Peels of Natsumikan The extraction from peels of natsumikan was conducted with various solvents (petroleum ether, ethyl ether, chloroform, acetone, ethanol and hot water). The yield of all extracts from $53 \mathrm{~g}$ of dried peel powder was $17.6 \mathrm{~g}(33 \%)$. The appearance and yield of extracts are summarized in Table 1. A small amount of extracts $\mathbf{1}-\mathbf{3}$ was obtained by the extraction with lower polar solvents, while the yield of extracts $\mathbf{4}-\mathbf{6}$ with higher polar solvents was relatively large. Contents of auraptene in
Table 1. Extracts from Peels of Citrus natsudaidai ${ }^{a}$

\begin{tabular}{cllcc}
\hline \hline Extract & \multicolumn{1}{c}{ Solvent } & Appearance & Yield $(\mathrm{g})$ & $\begin{array}{c}\text { Auraptene } \\
\text { content }^{b)} \\
(\mathrm{mg} / \mathrm{g})\end{array}$ \\
\hline $\mathbf{1}$ & Petroleum ether & Oily & 0.43 & 26.6 \\
$\mathbf{2}$ & Ethyl ether & Oily & 0.07 & 1.10 \\
$\mathbf{3}$ & Chloroform & Oily & 0.34 & 1.06 \\
$\mathbf{4}$ & Acetone & Powder & 2.32 & 0.51 \\
$\mathbf{5}$ & Ethanol & Oily & 8.52 & 0.13 \\
$\mathbf{6}$ & Hot water & Powder & 5.96 & n.d. \\
\hline
\end{tabular}

a) The extracts were obtained from $53 \mathrm{~g}$ of dried peel powder. b) Auraptene content in the extracts was determined by HPLC. n.d.: Auraptene was not detected.

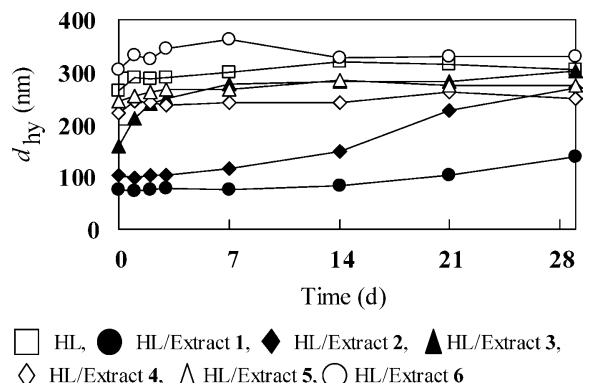

Fig. 1. Time Courses of $d_{\text {hy }}$ Change for HL and HL Including Extracts from Peels of Natsumikan

$[$ DMPC $]=3.0 \times 10^{-3} \mathrm{M},[$ Tween 20$]=3.3 \times 10^{-4} \mathrm{M},[$ Extract $]=2000 \mu \mathrm{g} / \mathrm{ml}$.

the extracts $\mathbf{1}-\mathbf{6}$ are also summarized in Table 1 . Most of the auraptene in the peels of natsumikan was extracted with petroleum ether into extract $\mathbf{1}$. Very little or no auraptene was found in extracts $\mathbf{2}-\mathbf{5}$ and $\mathbf{6}$, respectively.

Size and Stability of Hybrid Liposomes (HL) Including Extracts Figure 1 shows the time courses of mean hydrodynamic diameter $\left(d_{\text {hy }}\right)$ change for HL composed of $90 \mathrm{~mol} \%$ DMPC and $10 \mathrm{~mol} \%$ Tween 20 and those for the HL including extracts of natsumikan. HL alone was about $300 \mathrm{~nm}$ in diameter and stable for more than 1 month. The diameters of HL including extracts $\mathbf{4}-\mathbf{6}$ were almost constant (250$350 \mathrm{~nm}$ ), though the $d_{\text {hy }}$ of HL including extracts $\mathbf{1}-\mathbf{3}$ were smaller than that of HL and gradually increased with time. The HL size depends on the structure of included agents. $^{10,13,14)}$ That is, the cone-shape agents encapsulated in HL, which have larger polar head and/or smaller non-polar tail regions than those of membrane molecules, reduce the size of HL. ${ }^{14)}$ Plausibly, the hydrophobic cone-shape extracts were incorporated into $\mathrm{HL}$, so that the size and stability of HL including extracts $\mathbf{1}-\mathbf{3}$ would be changed.

Inhibitory Effects of Extracts of Natsumikan on the Growth of Tumor Cells Inhibitory effects of extracts from natsumikan and those encapsulated in HL on the growth of tumor cells (human lung carcinoma (RERF-LC-OK), human hepatoma (Hep-G2), human stomach tumor (GT3TKB) and B-16 mouse melanoma (B-16 melanoma) cells in vitro are shown in Figs. 2 and 3, respectively. Inhibitory effects of extracts $\mathbf{1}-\mathbf{3}$ encapsulated in HL were obtained, though no significant inhibitory effects of extracts 4-6 were observed (Fig. 2). Furthermore, the inhibitory effects of extracts $\mathbf{1}-\mathbf{3}$ encapsulated in HL were enhanced as compared with those of free extracts $\mathbf{1}-\mathbf{3}$ (Fig. 3). In particular, high inhibitory effects of extracts $\mathbf{1}-\mathbf{3}$ encapsulated in HL were obtained on the growth of B16-melanoma cells. No distinguished rela- 


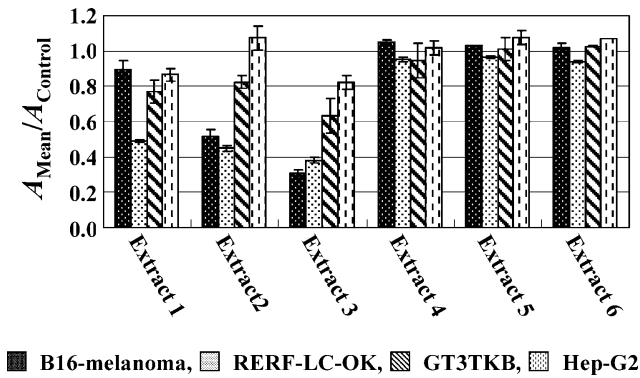

Fig. 2. Inhibitory Effects of Extracts from Peels of Natsumikan on the Growth of Various Tumor Cells

$[$ Extract $]=182 \mu \mathrm{g} / \mathrm{ml}$. Data presented are means; bars, S.D.s.

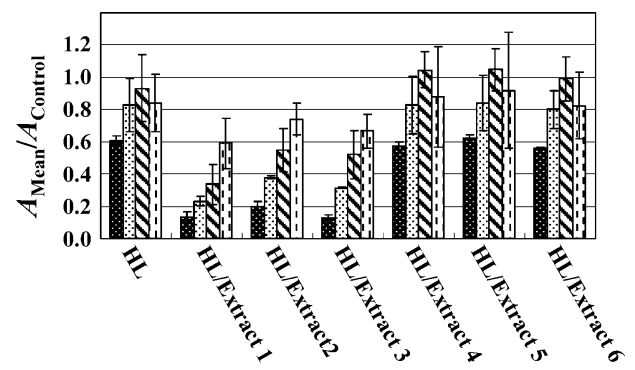

B16-melanoma, $\square$ RERF-LC-OK, $\mathbb{N}$ GT3TKB, 图 Hep-G2

Fig. 3. Inhibitory Effects of HL Including Extracts from Peels of Natsumikan on the Growth of Various Tumor Cells

$[$ DMPC $]=2.7 \times 10^{-4} \mathrm{M}$, [Tween 20] $=3.0 \times 10^{-5} \mathrm{M}$, [Extract $]=182 \mu \mathrm{g} / \mathrm{ml}$. Data presented are means; bars, S.D.s.
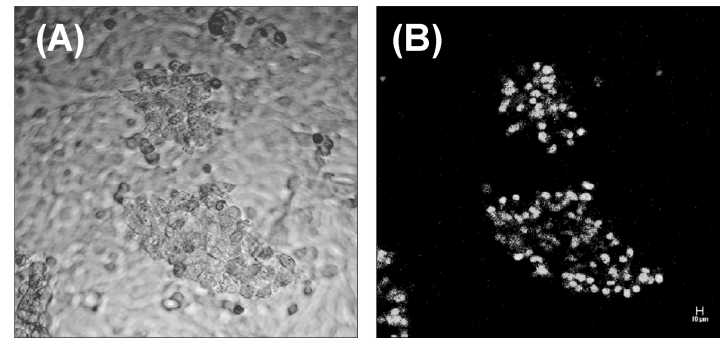

Fig. 4. Transmission (A) and Overlay (B) Images of Fluorescence Micrographs of B-16 Melanoma Cells Treated with HL Including Extract 1 and DNA Dyes (YO-PRO-1, PI) $12 \mathrm{~h}$

$[D M P C]=2.7 \times 10^{-4} \mathrm{M},[$ Tween 20$]=3.0 \times 10^{-5} \mathrm{M},[$ Extract $]=182 \mu \mathrm{g} / \mathrm{ml}$, incubation;

tionships between the inhibitory effect and auraptene content (Table 1) of extracts $\mathbf{1}-\mathbf{3}$ were observed. This result suggests that the extracts $\mathbf{1}-\mathbf{3}$ could contain not only auraptene but also other hydrophobic antitumor agents.

Induction of Apoptosis by Extracts from Natsumikan Encapsulated in HL Figure 4 shows the transmission (A) and overlay (B) images of fluorescence micrographs of B-16 melanoma cells treated with HL including extract $\mathbf{1}$ and DNA dyes, YO-PRO-1 and PI. Double staining assay of cell death with YO-PRO-1 and PI detects apoptotic and necrotic cells as green and red (or orange) fluorescent cells, respectively. ${ }^{15,16)}$ As shown in Fig. 4 (B), most of the cells treated with HL including extract 1 exhibited the green fluorescence. These results indicate that the HL containing extract 1 induced apoptosis in B16-melanoma cells.

Cytotoxicity of Extracts from Natsumikan against Normal Cells Cytotoxicity of extracts from natsumikan was examined using normal human fibroblast (WI-38) cells in

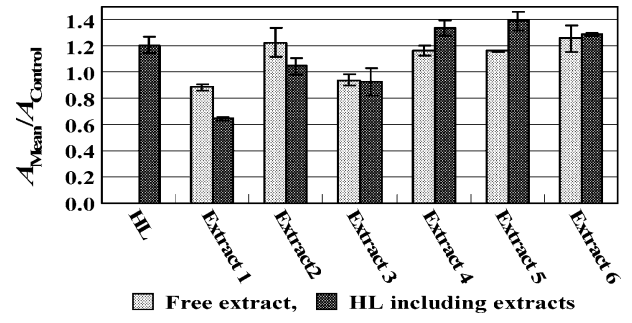

Fig. 5. Inhibitory Effects of HL Including Extracts from Peels of Natsumikan on the Growth of WI-38 Cells

$[\mathrm{DMPC}]=2.7 \times 10^{-4} \mathrm{M}$, [Tween 20] $=3.0 \times 10^{-5} \mathrm{M}$, [Extract $]=182 \mu \mathrm{g} / \mathrm{ml}$. Data presented are means; bars, S.D.s.

vitro. The results are shown in Fig. 5. No significant inhibitory effects on the growth of WI-38 cells were observed for extracts $\mathbf{2}$ and $4-6$. Extract 1 and 3 and those encapsulated in HL slightly inhibited the growth of WI-38 cells, but the inhibitory effects were even less than those of B-16 melanoma and RERF-LC-OK cells. These results suggest that the HL including extracts $\mathbf{1}-\mathbf{3}$ have little toxicity toward WI-38 cells and could inhibit the growth of tumor cells without considerable side effects on normal cells. Further works on the identification of antitumor compounds in the extracts are now under investigation.

Acknowledgements This research was supported in part by a Grant-in-Aid for Science Research from the Ministry of Education, Culture of Japan (Nos. 14350439, 15500335). We thank Kumamoto Kanzume Co., Ltd. for providing peels of natsumikan.

\section{REFERENCES}

1) Nishino H., "Gankagakuyobou no Saizensen," Iyaku (Medicine and Drug) Journal Co., Ltd., Osaka, 2000, p. 29.

2) Murakami A., Kuki W., Takahashi Y., Yonei Y., Nakamura Y., Ohta Y., Ohigashi H., Koshimizu K., Cancer Res., 88, 443- 452 (1997).

3) Tanaka T., Kawabata K., Kakumoto M., Makita H., Hara A., Mori H., Satoh K., Murakami A., Kuki W., Takahashi Y., Yonei H., Koshimizu K., Ohigashi H., Carcinogenesis, 18, 2155-2161 (1997).

4) Tanaka T., Kawabata K., Kakumoto M., Mori H., Murakami A., Kuki W., Takahashi Y., Yonei H., Koshimizu K., Ohigashi H., Carcinogenesis, 19, 425-431 (1998).

5) Ueoka R., Matsumoto Y., Moss R. A., Swarup S., Sugii A., Harada K., Kikuchi J., Murakami Y., J. Am. Chem. Soc., 110, 1588-1595 (1988).

6) Matsumoto Y., Imamura C., Ito T., Taniguchi C., Ueoka R., Biol. Pharm. Bull., 18, 1456-1458 (1995).

7) Ueoka R., Matsumoto Y., Kanno A., Tsuzaki K., Ichihara H., Biol. Pharm. Bull., 23, 1262-1263 (2000).

8) Ueoka R., Matsumoto Y., Ichihara H., Kiyokawa T., "Am. Chem. Soc. Symposium Series 830," Chap. 14, ed. by Marten M. R., Park T. H., Nagamune T., Am. Chem. Soc. Books, Washington, 2002, pp. 177189 .

9) Kitamura I., Kochi M., Matsumoto Y., Ueoka R., Kuratsu J., Ushio Y., Cancer Res., 56, 3986-3992 (1996).

10) Yamamoto S., Nakano K., Ishikawa C., Yamamoto M., Matsumoto Y., Iwahara M., Furusaki S., Ueoka R., Bio. Chem. Eng. J., 12, 125-130 (2002).

11) Kariyone T., Matsuno T., Chem. Pharm. Bull., 1, 119-122 (1953).

12) Ishiyama M., Shiga M., Sasamoto K., Mizoguchi M., He P.-G., Chem. Pharm. Bull., 41, 1118-1122 (1993).

13) Mitchell D. J., Ninham B. W., J. Chem. Soc., Faraday Trans., 77, 601-621 (1981).

14) Israelachvili J. N., Mitchell D. J., Ninham B. W., Biochem. Biophys. Acta, 470, 185-201 (1977).

15) Idziorek T., Estaquier J., De Bels F., Ameisen J. C., J. Immunol. Methods, 185, 249-258 (1995).

16) Fish K. N., Schmid S. L., Damke H., J. Cell Biol., 150, 145-154 (2000). 